\title{
Two-Stage-to-Orbit Transporting System Combining Microwave Rocket and Microwave Thermal Rocket for Small Satellite Launch
}

\author{
By Kaoru Kakinuma, ${ }^{1)}$ Masafumi FukUnARI,${ }^{1)}$ Toshikazu YAmaguchI, ${ }^{1)}$ Yusuke NaKamuRA, ${ }^{1)}$ Hiroyuki KoIzumi,${ }^{1)}$ \\ Kimiya KOMURASAKI ${ }^{1)}$ and Kevin PARKIN ${ }^{2)}$ \\ 1) The University of Tokyo, Kashiwa, Chiba, Japan \\ 2) Carnegie Mellon University, Silicon Valley Campus, California, USA
}

(Received August 1st, 2015)

\begin{abstract}
This paper proposes a two-stage-to-orbit launch system comprised of a Microwave Rocket 1st stage and a Microwave Thermal Rocket 2 nd stage. The air-breathing 1st stage improves payload fraction relative to a single-stage-to-orbit system and carries the 2nd stage above the atmosphere and into range of its beam director. For the 1st stage task, a Microwave Rocket is superior to an unmanned aerial vehicle because it is simpler, faster, and reaches higher altitude at higher speed. In addition, we present a new trajectory that eliminates power beaming at low elevation angles and improves system performance. This combination of factors reduces the propellant needed in the 2 nd stage, which in turn increases payload fraction by a remarkable factor of 3 times.
\end{abstract}

Key Words: Beamed Energy Propulsion, Gyrotron, Microwave, Wireless Power Transfer

\section{Nomenclature}

$\begin{array}{cll}A & : & \text { cross sectional area } \\ C_{\mathrm{D}} & : & \text { drag coefficient } \\ D & : & \text { drag } \\ m & : & \text { rocket mass } \\ p & : & \text { pressure } \\ r & : & \text { geocentric radius } \\ T & : & \text { thrust } \\ t & : & \text { time } \\ V & : & \text { velocity } \\ \beta & : & \text { longitude } \\ \theta & : & \text { height } \\ \mu & : & \text { standard gravitational parameter for earth } \\ \rho & : & \text { air density } \\ \text { Subscripts } & & \\ \text { a } & : & \text { ambient } \\ \text { ple } & : & \text { final } \\ \text { W } & : & \text { thrust wall }\end{array}$

\section{Introduction}

When we transport something to space, the how of carrying out this activity still remains the same since Sputnik was launched for the first time by chemical rockets. Even though many

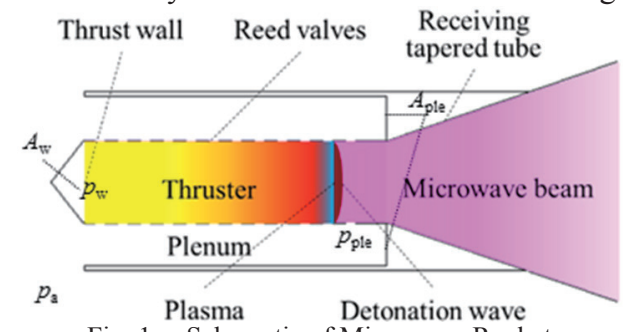

Fig. 1. Schematic of Microwave Rocket. problems of this approach have been pointed out, the most critical one is the cost. The launch cost remains around $\$ 10,000$ per kilogram of payload, and a breakthrough of further cost reduction cannot be detected with the chemical rocket at present. The specific impulse of conventional chemical rockets is about $450 \mathrm{~s}$ at maximum, resulting in low payload fraction of about $3 \%$. Additionally, the liquid rocket engine requires complex and expensive systems such as turbo-pumps, and usually, these are expended increasing total cost. Various ways of space transportation have been researched to break the deadlock, and Beamed Energy Propulsion (BEP) is one of the most promising future launch systems because it is expected to realize high-rate low-cost space access. High payload fraction, small environmental burden, and semi-permanent repetitive utilization of the launch system can be achieved because its propulsive energy is supplied externally by an electromagnetic beam radiated from a ground facility ${ }^{1,2}$.

At the University of Tokyo, Microwave Rocket (MR), which is one of several BEP approaches, has been researched and developed for practical use. MR is a kind of pulsed detonation engine (PDE) with an exceedingly simple configuration shown in Fig. 1. The concept was invented in 2003 and a successful experiment of thrust generation was demonstrated for the first time in the world ${ }^{3-5)}$. The thrust is generated by high pressure due to the detonation wave that is supported by the plasma absorbing the microwave beam energy supplied from the ground, using ambient air as propellant. The energy source and the propellant remain off board. Moreover, complex structures such as turbo-pump are unnecessary and provide on board kilogram savings. The specific impulse of MR is equivalent to infinity during atmospheric flight. Meanwhile at NASA, Microwave Thermal Rocket (MTR), ${ }^{6-8)}$ which is also one of BEP concepts and an analogy of the nuclear thermal

Copyright $\bigcirc 2016$ by the Japan Society for Aeronautical and Space Sciences and ISTS. All rights reserved. 

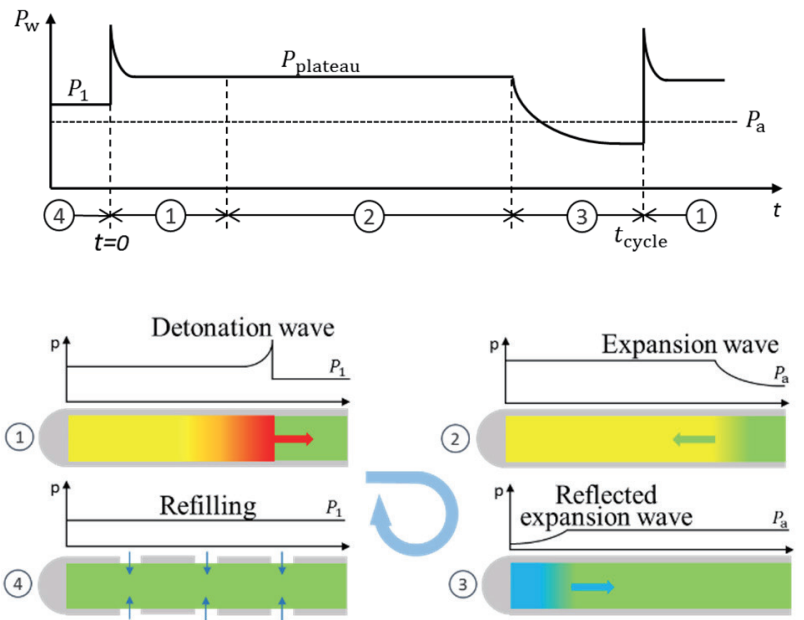

Fig. 2. Schematic of pressure history at the thrust wall (Top), and of PDE cycle (Bottom). Note that the process of refilling is assumed to be conducted instantaneously so its time duration is neglected in the top.

rocket, using microwave beam rather than neutron as an energy source, is studied and planned for a 1st orbital launch of $50 \mathrm{~kg}$ vehicle by $2020^{9)}$. In this concept, MTR is carried into the beam range by an unmanned aerial vehicle (UAV), then launched from above the ground and propelled within the beam range.

This paper proposes a two-stage-to-orbit (TSTO) launch system whose 1st stage is MR as alternative to the UAV. The UAV cannot reach altitude much above $25 \mathrm{~km}$ and takes an hour or more to reach that height. Such a long flight costs more than the unit cost of the 1st stage MR for the fuel, and furthermore for an $\mathrm{LH}_{2}$ 2nd stage, means complex equipment is needed for the prevention of $\mathrm{LH}_{2}$ boiling off and oxygen ice build-up on the outside of the tank. (this highlighted sentence is not clear, let's discuss later) In comparison, MR can reach more than $30 \mathrm{~km}$ with a velocity of at least $1 \mathrm{~km} / \mathrm{sec}$ in a few minutes, and costs considerably less (even with the inclusion of the construction cost of beam director) than the development cost for the UAV. To compare with the UAV case, the TSTO ascent trajectory was calculated, and the scale of ground facilities and costs were estimated.

\section{Microwave Rocket Thrust Model}

The thrust generation model of the MR is explained as a PDE cycle ${ }^{10)}$ and there are four steps in the cycle (Fig.2). The 1 st step is the propagation of the detonation wave, and a pressure increment process is calculated assuming the Chapman-Jouguet condition. The 2 nd step is the propagation of the expansion wave. The high pressure at the thrust wall is maintained during this process. The 3rd step is the reflection of the expansion wave and a pressure decrement process. The reflected expansion wave is computed assuming isentropic expansion. The 4th step is the refilling and the pressure recovery. Generally, the thrust is generated by the pressure difference between the thrust wall and ambient atmosphere (see Fig.1). The average thrust of a cycle $\bar{T}$ can be written as follows.

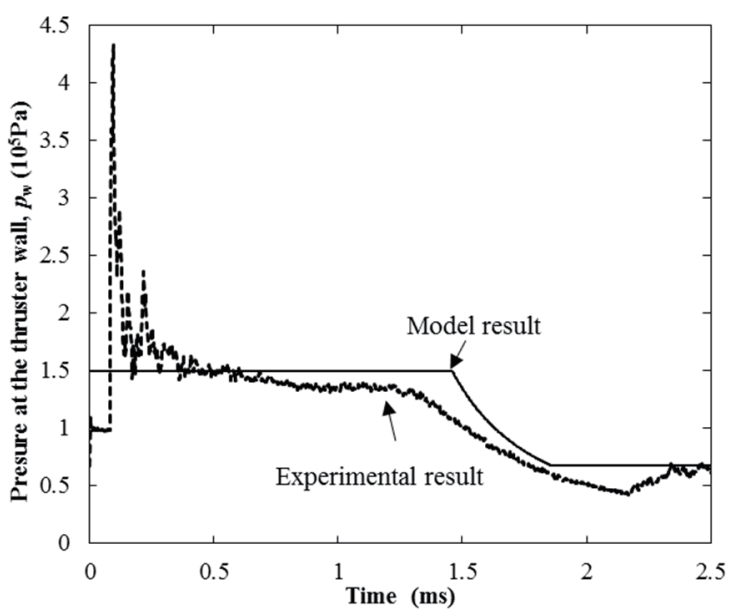

Fig. 3. Pressure history at the thrust wall.

$$
\bar{T}=\frac{1}{t_{\text {cycle }}} \int_{0}^{t_{\text {corle }}}\left[\left(p_{w}-p_{a}\right) A_{w}+\left(p_{a}-p_{\text {ple }}\right) A_{\text {ple }}\right] d t
$$

The plenum is the space for the thruster refilling and assumed to be in stagnation condition. The refilling is assumed to be conducted instantaneously at the point of the negative pressure in the thruster, and obeys the adiabatic gas mixing law. Figure 3 draws a comparison between computation and experimental data of the $p_{\mathrm{w}}$. The experimental data was measured using the gyrotron as a beam source. The thruster length and diameter in the experiment were $397.5 \mathrm{~mm}$ and $60 \mathrm{~mm}$. The pressure increment and its duration time for both computation and experiment show good agreement which indicate that the model can simulate the detonation phenomena in the thruster tube effectively.

\section{Trajectory Analysis}

In this analysis, the 2-dimentional, 2-degree-of-freedom, equation of motion with respect to a mass point is solved in the polar coordinate (Fig.4), using Runge-Kutta 4th order method. The earth is treated as a rotating sphere, therefore the gravity follows the inverse-square law. The atmospheric state is calculated from 1976 U.S. standard atmosphere ${ }^{11)}$. The thrust and body axis are on the same line, neglecting the deflection angle of the thrust. The external forces applied to the body are the thrust, the gravity, and the drag, neglecting the lift. The wind is assumed to be much smaller than the speed, so the influence of the wind is neglected. The equations of motion are as follows.

$$
\begin{gathered}
\frac{d^{2} r}{d t^{2}}=r\left(\frac{d \theta}{d t}\right)^{2}-\frac{\mu}{r^{2}}+\frac{(\bar{T}-D) \sin \beta}{m} \\
\frac{d^{2} \theta}{d t^{2}}=-\frac{2}{r} \frac{d r}{d t} \frac{d \theta}{d t}+\frac{(\bar{T}-D) \cos \beta}{m r}
\end{gathered}
$$

Drag is calculated as follows.

$$
D=\frac{1}{2} \rho V^{2} A C_{D}
$$

The frontal area is assumed to be the maximum cross sectional area of the vehicle, or the cross sectional area of the receiving tapered tube. The drag coefficient is roughly evaluated using simplified analytical equations, ${ }^{10)}$ which consider the skin friction drag and the base drag. 


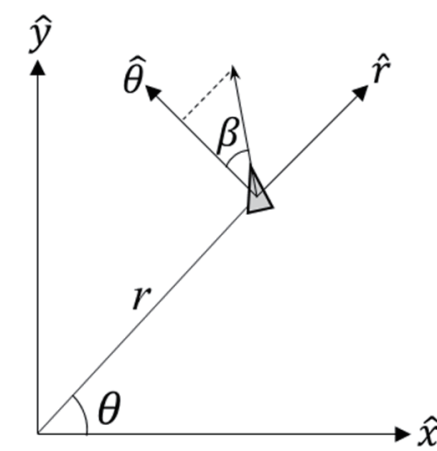

Fig. 4. Parameters in the polar coordinate.

\subsection{Problem setting}

A TSTO vehicle takes off vertically and delivers payload into a $300 \mathrm{~km}$ circular LEO. The 2nd stage is MTR whose specification is shown in table 1 , which is an equivalence of the UAV. After the cutoff of the 1st stage, the 2nd stage thrusts horizontally and propels itself within the beam range. The beam range for MTR is set to $150 \mathrm{~km}$ for comparative analysis. Using the values in table 1 and the rocket equation, the equivalent delta $\mathrm{V}$ of the $2 \mathrm{nd}$ stage is $9.5 \mathrm{~km} / \mathrm{s}$.

Table 1. Specification of MTR shown in 2).

\begin{tabular}{lc}
\hline Wet mass & $50 \mathrm{~kg}$ \\
Structural mass & $11 \mathrm{~kg}$ \\
Propellant mass & $37 \mathrm{~kg}$ \\
Payload mass & $2 \mathrm{~kg}$ \\
Payload fraction & $4 \%$ \\
Vacuum specific impulse & $721 \mathrm{sec}$ \\
Propellant mass flow & $0.37 \mathrm{~kg} / \mathrm{sec}$ of $\mathrm{H}_{2}$ \\
Absorbed power & $10 \mathrm{MW}$ \\
\hline
\end{tabular}

\subsection{Trajectory design and performance evaluation}

First of all, the simple replacement case in which UAV was just replaced by MR was investigated (Fig. 5). The velocities written in Fig. 5 are velocities relative to the earth surface. Rotational speed of the earth $(0.46 \mathrm{~km} / \mathrm{s})$ is not included. The computation result shown in Fig.5 was optimized by considering a tradeoff relationship between 1st stage and 2nd stage cutoff velocities with limitation on the beam range. An increase in $1^{\text {st }}$ stage cutoff velocity drives the vehicle away from the beam range in short time.

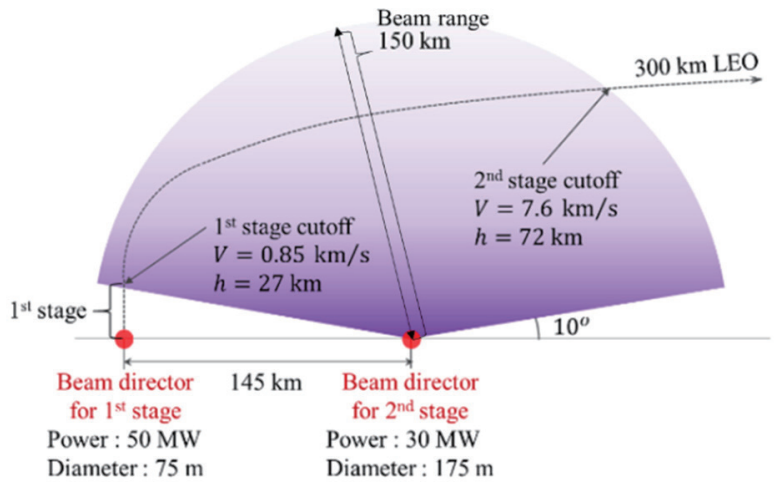

Fig. 5. Simple replacement of the UAV by MR.

The computation results indicate only double the payload fraction (table 2). This is because MR is able to propel only vertically, which leads to shorter range for propulsion of the $2^{\text {nd }}$ stage MTR.

Table 2. Comparison of the simple replacement case.

\begin{tabular}{|c|c|c|}
\hline $1^{\text {st }}$ stage & UAV & MR \\
\hline Propellant mass & $37 \mathrm{~kg}$ & $35 \mathrm{~kg}$ \\
\hline Payload mass & $2 \mathrm{~kg}$ & $4 \mathrm{~kg}$ \\
\hline Payload fraction & $4 \%$ & $7 \%$ \\
\hline
\end{tabular}

A new trajectory design is proposed to solve this problem and show the ability of MR. As shown in Fig. 6, the length of the intervals between beam directors is increased and the $1^{\text {st }}$ beam director is shared by both $1^{\text {st }}$ and $2^{\text {nd }}$ stage. The power output of $50 \mathrm{MW}$ and the beam range of $34 \mathrm{~km}$ for the $1^{\text {st }}$ stage has capacity equivalent to the beam range of $105 \mathrm{~km}$ for $2^{\text {nd }}$ stage. After the $2^{\text {nd }}$ stage thrust halt at the edge of the $1^{\text {st }}$ beam director beam range, it has a sub-orbital flight until the entrance into the beam range of the $2^{\text {nd }}$ beam director, and propels itself again within the beam range to get the rest of $\Delta V$. This trajectory design brings out the potential of MR and improve the performance of the whole launch system. This trajectory was optimized in terms of payload fraction whiles fixing the beam parameters of the $2^{\text {nd }}$ beam source. The payload fraction is about 3 times larger than the UAV case (Table 3). This remarkable performance improvement results from small velocity losses of $2^{\text {nd }}$ stage MTR compared with the case using

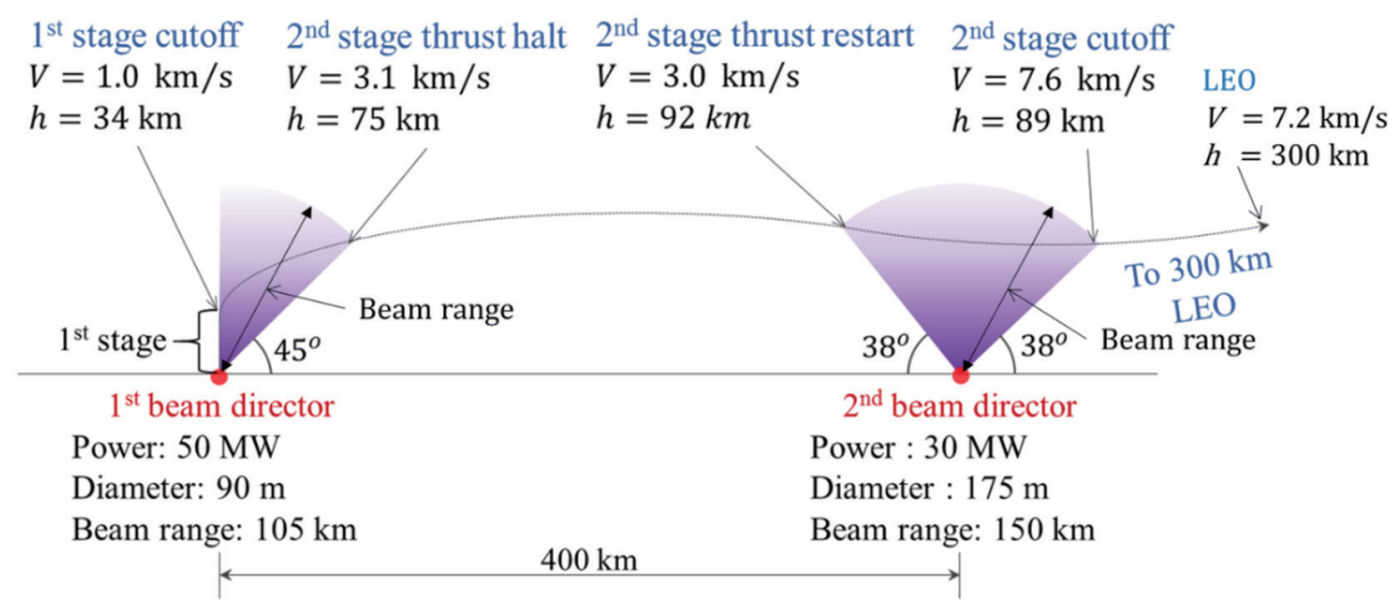

Fig. 6. Newly proposed trajectory sharing $1^{\text {st }}$ beam director. 
UAV. Delta-V budget breakdown is shown in Table 4, which includes gravity loss after $2^{\text {nd }}$ stage cutoff. This budget indicates that the role of $1^{\text {st }}$ stage MR is to compensate velocity losses because of its only vertical acceleration. The total delta- $\mathrm{V}$ is $7.20 \mathrm{~km} / \mathrm{sec}$, which is almost equal to the orbital velocity at 300 $\mathrm{km}$ LEO

Table 3. Comparison of the newly proposed trajectory case

\begin{tabular}{lcc}
\hline $1^{\text {st }}$ stage & UAV & MR \\
\hline Propellant mass & $37 \mathrm{~kg}$ & $37 \mathrm{~kg}$ \\
Payload mass & $2 \mathrm{~kg}$ & $8 \mathrm{~kg}$ \\
Payload fraction & $4 \%$ & $13 \%$ \\
\hline
\end{tabular}

Table 4. Delta-V budget $(\mathrm{km} / \mathrm{sec})$.

\begin{tabular}{|c|c|c|c|}
\hline & $1^{\text {st }}$ stage & $2^{\text {nd }}$ stage & Total \\
\hline Thrust & +6.38 & +6.97 & +13.35 \\
\hline Drag & $\begin{array}{l}-\quad 4.59 \\
\end{array}$ & 0.17 & 4.76 \\
\hline Gravity & $\begin{array}{l}-\quad 0.79 \\
\end{array}$ & 0.60 & 1.39 \\
\hline Total & 1.00 & 6.20 & 7.20 \\
\hline
\end{tabular}

\section{Beam Facility}

The most different from conventional launch system is the microwave beam facility on the ground. Generally, the construction cost of the beam facility accounts for a large percentage of the whole cost relating to BEP launch system. However, it can be amortized in the future scale of launch system because the vehicle itself is not expensive and expected to be launched repetitively and frequently.

The beam facility roughly consists of power storage, beam production and beam transmission system. ${ }^{6}$ Flywheel batteries are suitable for power storage to supply large electrical power over a few minutes to the vehicle,(Do you supply electric power directly to the vehicle?) which charge in between launches and discharge rapidly during flight. The microwave beam is produced by a network of MW-class gyrotron, which has already been used to heat plasma in nuclear fusion research. For the beam transmission, phased array antenna is projected to be selected because no mechanical movement is needed to change the beam emitting angle due to phase control. High power and a large aperture can be achieved with the system (Fig.7).

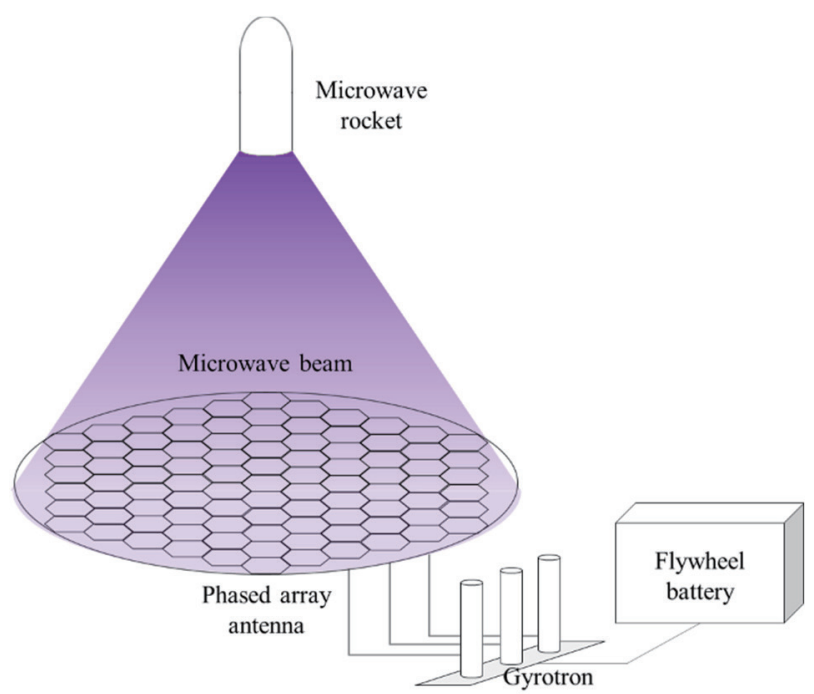

Fig. 7. Schematic of the beam facility.
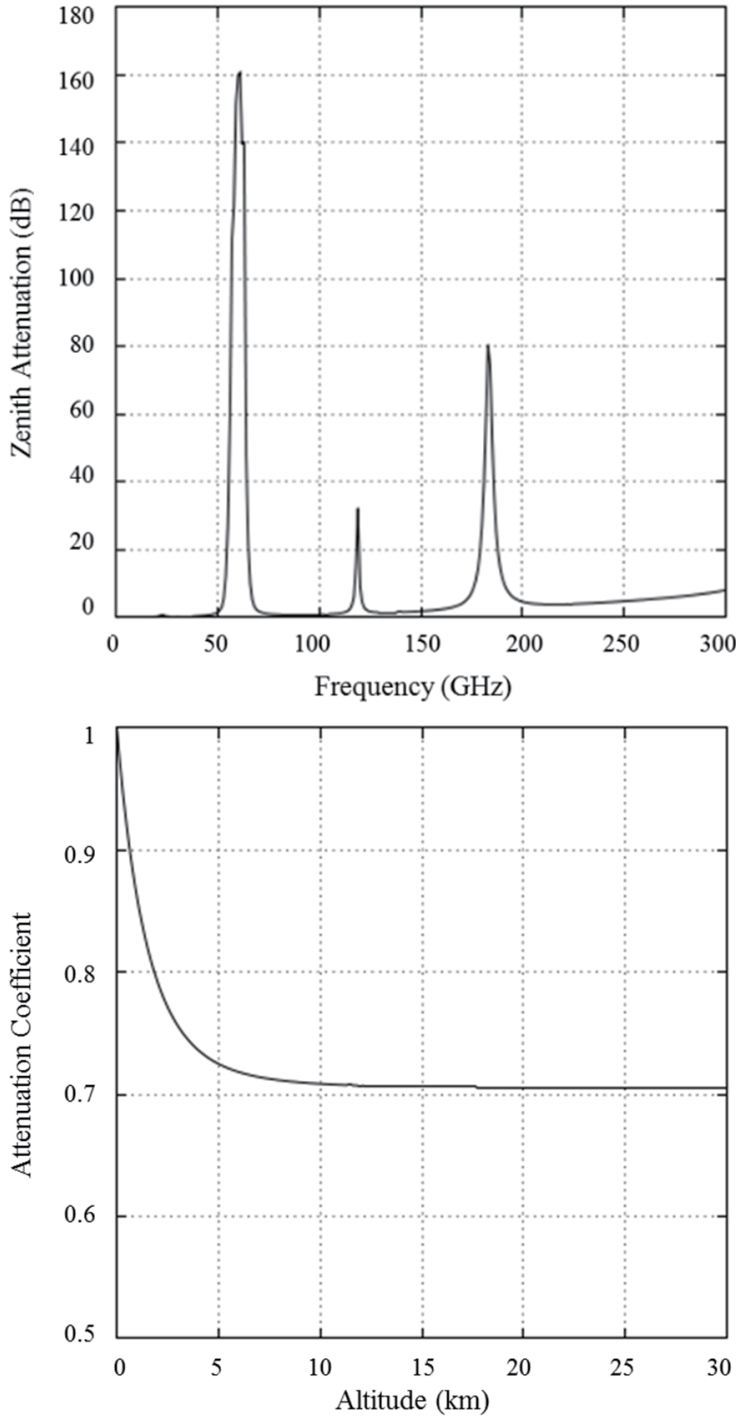

Fig. 8. Zenith attenuation calculated by the Line-by-Line method (Top), and the attenuation coefficient as function of altitude (Beam frequency $140 \mathrm{GHz}$ ) (Bottom).

When considering the beam transmission, the attenuation of the microwave beam has to be taken into account. The atmospheric attenuation of the microwave beam is calculated by the Line-by-Line method ${ }^{12)}$. Only zenith attenuation is considered and the computed result focused on milli-wave zone is shown in Fig. 8. In this analysis, the beam frequency of 140 $\mathrm{GHz}$ is selected because of its relatively low attenuation. According to Fig. 8, about $30 \%$ of the microwave beam attenuates in the atmosphere. This attenuation was considered in the trajectory analysis above.

\section{Cost Estimate}

The cost estimate of the UAV case is shown in table 5. This includes only the fuel cost and other costs relating to the UAV such as developing cost, production cost and maintenance cost are excluded. In Ref.9, the launch cost of the UAV case was estimated to be lower than that of chemical rockets. In the same way described in Ref.9, the cost of the vehicle and the beam facilities in the latter case of replacement by MR is estimated. 
Table 6 shows the vehicle launch cost, and table 7 shows the beam facility cost.

Table 5. Cost estimate of the UAV case.

\begin{tabular}{ll}
\hline Vehicle launch cost & $\$ 40,428$ \\
Beam facility cost & $\$ 280 \mathrm{M}$ \\
\hline
\end{tabular}

Table 6. Vehicle launch cost estimate breakdown.

\begin{tabular}{|c|c|c|c|}
\hline Component & Mass (kg) & Cost $(\$)$ & Cost justification \\
\hline $\begin{array}{r}\text { MR } \\
\text { MTR }\end{array}$ & $\begin{array}{r}6.7 \\
46.688\end{array}$ & $\begin{array}{r}8,040 \\
15,062\end{array}$ & $\begin{array}{l}\text { Complex short run } \\
\text { aircraft rule of } \\
\text { thumb: } \$ 1,200 / \mathrm{kg} \\
\text { Based on Ref.9 }\end{array}$ \\
\hline Integration & & 23,102 & $\begin{array}{l}\text { Assumed equal to } \\
\text { component cost } \\
\text { 1st stage: } 50 \mathrm{MW}(81 \\
\text { sec, duty ratio = } \\
0.24) \text {, 2nd stage: } 50 \\
\mathrm{MW}(54 \text { sec), } 30 \\
\mathrm{MW}(46 \mathrm{sec}) \text {. } \\
\text { Based on industrial } \\
\text { rate of } \$ 0.1055 / \mathrm{kWh} \\
\text { for California on } \\
\text { May } 1,2013\end{array}$ \\
\hline Total & 53.388 & 46,352 & $\begin{array}{l}\text { Exclude operational } \\
\text { personnel cost and } \\
\text { initial R\&D }+ \text { beam } \\
\text { facility cost }\end{array}$ \\
\hline
\end{tabular}

Table 7. Beam facility cost estimate breakdown.

\begin{tabular}{|c|c|c|c|}
\hline Component & Scale & Cost $(\$)$ & Cost justification \\
\hline Gyrotron & $80 \mathrm{MW}$ & $8 \mathrm{M}$ & $\begin{array}{c}\text { Assuming } \\
\$ 0.1 \mathrm{M} / \mathrm{MW} \\
\text { Assuming } \$ 0.01\end{array}$ \\
\hline Flywheel & $1403 \mathrm{kWh}$ & $14 \mathrm{M}$ & $\mathrm{M} / \mathrm{kWh}$ \\
\hline 1st Antenna & $90 \mathrm{~m}$ dia. & $173 \mathrm{M}$ & Based on Ref.9 \\
\hline 2nd antenna & $175 \mathrm{~m}$ dia. & $293 \mathrm{M}$ & Based on Ref.9 \\
\hline Total & & $488 \mathrm{M}$ & \\
\hline
\end{tabular}

\section{Conclusion}

This paper proposed a TSTO launch system whose 1st stage is MR (instead of UAV) and 2nd stage is MTR. The comparison of the whole launch system is shown in table 8. By adopting MR as 1st stage and the trajectory shown in Fig. 6, the whole launch system has remarkable performance of 3 times larger payload fraction, and the launch cost per unit mass of payload is only one quarter as much, compared with the case in which a UAV carries MTR. These differences are expected to be much more marked in a larger scale launch system.

To demonstrate an $8 \mathrm{~kg}$ satellite launch, the beam facility construction costs $\$ 490 \mathrm{M}$, the vehicle costs $\$ 46 \mathrm{k}$, and the electricity costs $\$ 150$.(Electricity cost of USD 150 seems unrealistic!!! )
Table 8. Comparison of whole launch system.

\begin{tabular}{lrcc}
\hline 1st stage & UAV & MR & Ratio \\
\hline Payload mass & $2.0 \mathrm{~kg}$ & $8.0 \mathrm{~kg}$ & 4 \\
Payload mass fraction & $4.0 \%$ & $13 \%$ & 3.25 \\
Launch cost & $\$ 40 \mathrm{k}$ & $\$ 46 \mathrm{k}$ & 1.15 \\
$\begin{array}{l}\text { Lunch cost per unit } \\
\text { mass of payload }\end{array}$ & $20 \mathrm{k} \$ / \mathrm{kg}$ & $5.8 \mathrm{k} \$ / \mathrm{kg}$ & 0.29 \\
$\begin{array}{l}\text { Beam facility } \\
\text { construction cost }\end{array}$ & $\$ 280 \mathrm{M}$ & $\$ 490 \mathrm{M}$ & 1.75 \\
\hline
\end{tabular}

\section{Acknowledgement}

This work was supported by Grant-in-Aid for Scientific Research (A), Grant No. 15H02320.

\section{References}

1) Claude Phipps and Mitat Birkan, et al:: Review: Laser-Ablation Propulsion, Journal of Propulsion and Power, Journal of propulsion and power, 26, No. 4 (2010), pp. 609-637.

2) Komurasaki, K. and Wang, B.: Laser Propulsion, in Encyclopedia of Aerospace Engineering, R. Blockley and W. Shyy (eds). John Wiley \& Sons Ltd, Chichester, UK, pp. 1351-1360.

3) Oda, Y., Nakagawa, T., Komurasaki, K., Takahashi, K., Kasugai, A., Sakamoto, K. and Imai, T.: An observation of plasma inside of microwave boosted thruster, In BEAMED ENERGY PROPULSION: Second International Symposium on Beamed Energy Propulsion, 702, No. 1 (2004), pp. 399-406.

4) Nakagawa, T., Mihara, Y., Komurasaki, K., Takahashi, K., Sakamoto, K. and Imai, T.: Propulsive impulse measurement of a microwave-boosted vehicle in the atmosphere, Journal of spacecraft and rockets, 41, No. 1 (2004), pp.151-153.

5) Fukunari, M., Arnault, A., Yamaguchi, T. and Komurasaki, K.: Replacement of Chemical Rocket Launchers by Beamed Energy Propulsion, Applied Optics, 53, Issue 31 (2014), pp. I16-I22.

6) Parkin, Kevin LG, Leo D. DiDomenico, and Fred EC Culick.: The microwave thermal thruster concept, Second International Symposium on Beamed Energy Propulsion, 702 (2004), pp. 418-429.

7) Parkin, Kevin LG, and Fred EC Culick.: Feasibility and Performance of the Microwave Thermal Rocket Launcher, Second International Symposium on Beamed Energy Propulsion, 702 (2004), pp.407-417.

8) Murakami, David D., and Kevin L. Parkin.: An Overview of the NASA Ames Millimeter-Wave Thermal Launch System, 48th AIAA/ASME/SAE/ASEE Joint Propulsion Conference, AIAA 20123741, Atlanta, Georgia, 2012.

9) Parkin, K., Myrabo, L., Mikula, J., and Dickey, D.: Overview of the Millimeter-Wave Thermal Launch System (MTLS) Project, International High Power Laser Ablation and Beamed Energy Propulsion, Santa Fe, NM, 2014.

10) Arnault, A.: Trajectory Analysis of Microwave Launches with Costs Perspectives, Master's Thesis, Advanced Energy Dept., the University of Tokyo, 2012.

11) Atmosphere, US Standard. National Oceanic and Atmospheric Administration. National Aeronautics and Space Administration, United States Air Force, Washington, DC (1976).

12) Rec. ITU-R P.676-3: “Attenuation by Atmospheric Gases", ITU-R Recommendations, Volume 1997 P Series Part 1, pp.244-260, ITU, Geneva (1998). 